\title{
Chemiluminescence analysis of the activity of Pecten maximus hemocytes stimulated with zymosan and host-specific Rickettsiales-like organisms
}

\author{
G. Le Gall, E. Bachère*, E. Mialhe \\ IFREMER, LABEIM Laboratoire de Biologie et d'Ecologie des Invertébrés Marins, URPIGM Unité de recherche en Pathologie, \\ Immunologie et Génétique Moléculaire, BP 133, F-17390 La Tremblade, France
}

\begin{abstract}
During a study of Rickettsiales-like organisms (RLO) in Pecten maximus gill, histological observation of free RLO in hemolymph led us to consider interactions between the pathogen and the hemocytes. Firstly, the production of oxygen radicals by hemocytes was established using a luminolenhanced chemiluminescence method with zymosan as stimulant. The effects of several inhibitors of oxidative metabolism were investigated. The internalization of RLO into hemocytes was demonstrated by electron microscopy but was not related to chemiluminescent activity. The possible involvement of RLO acid phosphatase as the inhibitor of respiratory burst was assessed.
\end{abstract}

\section{INTRODUCTION}

At the end of each winter from 1986 to 1988 , mass mortalities were reported in Pecten maximus beds at Saint-Brieuc Bay (North Brittany). A histological study, performed in March 1987, on different tissues of bay scallops from Saint-Brieuc Bay found Rickettsiales-like organisms (RLO) in parasitophorous vacuoles of gill endothelial cells (Le Gall et al. 1988). Because several cases of RLO have been associated with mortalities of bivalve species (Buchanan 1978, Comps \& Raimbault 1978) and particularly of scallops (Gulka et al. 1983), the Pecten maximus RLO were considered to be involved in the recent mortalities.

Moreover, these histological investigations showed that RLO were frequently observed free in the hemolymph, and that infected cells were generally clustered. These observations have to be considered in regard to host-pathogen interactions. Indeed, the free RLO, discharged from disrupted infected cells, may be involved in cell-to-cell transmission of microorganisms. Their momentary localization in hemolymph raised the question of their interactions with host hemocytes. In Mollusca, hemocytes represent the primary effector

- Author for correspondence component in defense functions, by using phagocytosis or encapsulation (Bang 1975, Anderson 1977, Sminia \& Van Der Knaap 1987). Recently, the production of toxic oxygen radicals has been histochemically demonstrated for hemocytes of Patinopecten yessoensis (Nakamura et al. 1985); it can also be detected by chemiluminescence in response to a phagocytic stimulus. This phenomenon, originally described by Allen et al. (1972), is the result of the production of toxic free oxygen radicals by oxidative metabolism and is known as respiratory burst. Oxidative metabolism constitutes 1 of the 2 antimicrobial mechanisms established in the vertebrate phagocytic process, the other one being related to the enzymatic process (Thomas et al. 1988).

The generation of oxygen radicals is currently investigated by luminol-enhanced chemiluminescence (CL), a method which amplifies the native light emitted by excited molecules (Allen \& Loose 1976, Prendergast \& Proctor 1981). By referring to vertebrate phagocytic cells (Roos 1980), this methodology has been developed for several gastropod species - Lymnaea stagnalis (Dikkeboom et al. 1987), Planorborius corneus, Helix aspersa (Dikkeboom et al. 1988) and Biomphalaria glabrata (Shozawa 1986) - and recently for oysters (Larson et al. 1989, Bachère et al. 1991). 
The present work aims at analysing the respiratory burst of Pecten maximus hemocytes by CL and focuses on interactions of the hemocytes with host-specific RLO, taking into account the frequent observation of free procaryotes in hemolymph in the course of infections.

\section{MATERIALS AND METHODS}

Specimens. For purification of RLO and hemolymph collection, 2- to 3-yr-old bay scallops were dredged from the bay of Saint-Brieuc (Brittany), an area which has been chronically affected by rickettsiosis for $4 \mathrm{yr}$.

Parasites. RLO were isolated and purified from infected bay scallop gills by successive differential and isopycnic centrifugations. Purified parasite viability was verified using an acridine orange and ethidium bromide assay (Parks et al. 1979). Parasite numbers were determined microscopically using a Mallassez blood-counting cell.

Hemolymph collection. The scallops were kept opened by force and their bodies were thoroughly washed with sterile seawater (SSW). Hemolymph was then withdrawn from the pericardial cavity and simultaneously diluted $1 / 1$ in modified anti-aggregant Alsever solution (Bachère et al. 1988).

Chemiluminescence assay. General protocol: Generation of chemiluminescence was measured with a liquid scintillation counter (Tri-Carb 2200 CA Packard) in the out-of coincidence mode. The counter was set on repeated cycles and sequential counts were made at 0.5 min intervals during $5 \mathrm{~h}$ periods. All the assays were performed at room temperature in plastic scintillation vials containing the hemocytes suspended in a final volume of $2 \mathrm{ml}$ completed with SSW. The luminol (5-amino-2,3-dihydro-1,4-phthalazinedione), stored $(0.1 \mathrm{M})$ in dimethyl sulfoxide (DMSO), was diluted in SSW immediately before use to obtain a final concentration of $10^{-4} \mathrm{M}$. It has been shown that this low concentration of DMSO has no effect on the CL response (Bachère et al. unpubl. results). The $C L$ base activity of the hemocytes was recorded for a run before adding the stimulants. A non-stimulated control prepared from the same hemolymph sample was always analysed in parallel.

Experimental parameters: For stimulation of hemocyte phagocytic activity, zymosan particles (Zymosan A, Sigma) at $40 \mathrm{mg} 10 \mathrm{ml}^{-1}$ were suspended in SSW and boiled for $30 \mathrm{~min}$, washed twice and then resuspended in SSW before being divided into aliquots and stored at $-20^{\circ} \mathrm{C}$. The aliquots were thawed and counted in a Mallassez cell immediately before use. The CL experiments were performed with 80 zymosan particles per hemocyte, this ratio eliciting an optimal response (Le Gall et al, 1989).
Hemocyte quantity: For all the experiments, a set of vials was prepared, each containing $2 \times 10^{5}$ hemocytes from the same hemolymph sample collected into an equal volume of Alsever solution. Because Alsever solution concentration interferes with the $\mathrm{CL}$ response unless the final concentration is under $2.5 \%$ (data not shown), only those hemolymph withdrawals containing more than $2 \times 10^{6}$ hemocytes $\mathrm{ml}^{-1}$ (hemolymph/ Alsever) were used. These samples were diluted with SSW to give $2 \times 10^{5}$ hemocytes in $2 \mathrm{ml}$, this final volume comprising luminol and the stimulant suspension (zymosan or RLO).

Inhibition of phagocytosis: The inhibitory effect of cytochalasin $B$ was determined at a final concentration of $10 \mu \mathrm{g} \mathrm{ml}^{-1}$ by addition to the hemocyte suspension just before starting the phagocytic stimulation.

Luminol-enhanced $\boldsymbol{C L}$ inhibitors: Effects of some luminol-enhanced CL inhibitors were determined by adding each to the assay vials at the time of the CL peak induced by zymosan stimulation. The final concentrations of inhibitors tested were 80 and $10 \mu \mathrm{g}$ superoxide dismutase (SOD) $\mathrm{ml}^{-1}, 65 \mu \mathrm{g}$ sodium azide $\left(\mathrm{NaN}_{3}\right) \mathrm{ml}^{-1}\left(10^{-3} \mathrm{M}\right)$ and $65 \mathrm{ug}$ potassium cyanide $(\mathrm{KCN}) \mathrm{ml}^{-1}\left(10^{-3} \mathrm{M}\right)$. Hemocyte viability after incubation in these different solutions was determined with an acridine orange/ethidium bromide test.

Stimulation with RLO: Hemocytes, after being stimulated with zymosan particles or left unstimulated, were stimulated with purified Pecten maximus RLO at a ratio of 80:1 RLO:hemocyte (Le Gall et al. 1989). Some assays were performed with live RLO, preincubated for $30 \mathrm{~min}$ in sodium L-tartrate $\left(3.3 \times 10^{-6} \mathrm{~mol}\right.$ $\left.\mathrm{ml}^{-1}\right)$ or in $\mathrm{NaN}_{3}\left(3 \times 10^{-4} \mathrm{~mol} \mathrm{ml}^{-1}\right)$. Other assays were similarly performed with RLO killed by formalin $(1 \%)$ or by heat $\left(100^{\circ} \mathrm{C}\right.$ for $\left.20 \mathrm{~min}\right)$, or with homogenates of RLO disrupted by ultrasound (100 W, $60 \mathrm{~s})$.

Electron microscopy for RLO phagocytosis assay. Hemolymph samples $(300 \mu \mathrm{l})$ were distributed in sterile Eppendorf tubes into which RLO were added (particle:hemocyte ratio of $50: 1$ ). After incubation (30 or 60 min, $18^{\circ} \mathrm{C}$ ), the samples were fixed with an equal volume of $1.25 \%$ glutaraldehyde, $2 \%$ paraformaldehyde in $0.1 \mathrm{M}$ sodium cacodylate- $\mathrm{HCl}$ buffer ( $\mathrm{pH} 7.4$ ), whose osmolarity was raised to $1000 \mathrm{mOsmol}$ with sucrose. Cells were rinsed 3 times with iso-osmotic phosphate-buffered saline and post-fixed in $1 \%$ osmium tetraoxide (30 min). After another wash, the pellets were preembedded in $1 \%$ agarose (Low Gel Temperature, Bio Rad) and processed for Epon 812 embedding by using an LKB Automatic Processor. Ultrathin sections (60 to $90 \mathrm{~nm}$ ) were double-contrasted with aqueous uranyl acetate and lead citrate (LKB Ultrostainer) and observed under a Jeol 1200 CX electron microscope 


\section{RESULTS}

\section{Hemocyte chemiluminescence activity}

Luminol-enhanced CL methodology was applied to search for Pecten maximus hemocyte oxidative metabolism using zymosan particles as phagocytosis stimulants. Whatever the assay, control and experimental samples were strictly equivalent since they were prepared from the same withdrawn hemolymph sample.

Results obtained with hemocytes from 3 scallops are shown in Fig. 1. Base activities were very low for nonstimulated hemocytes. After zymosan stimulation, CL activities increased rapidly, reaching maximum values after about $1 \mathrm{~h}$, and then decreased slowly over several hours. Although the CL response patterns were similar, some intensity and duration differences were observed in individual scallops.

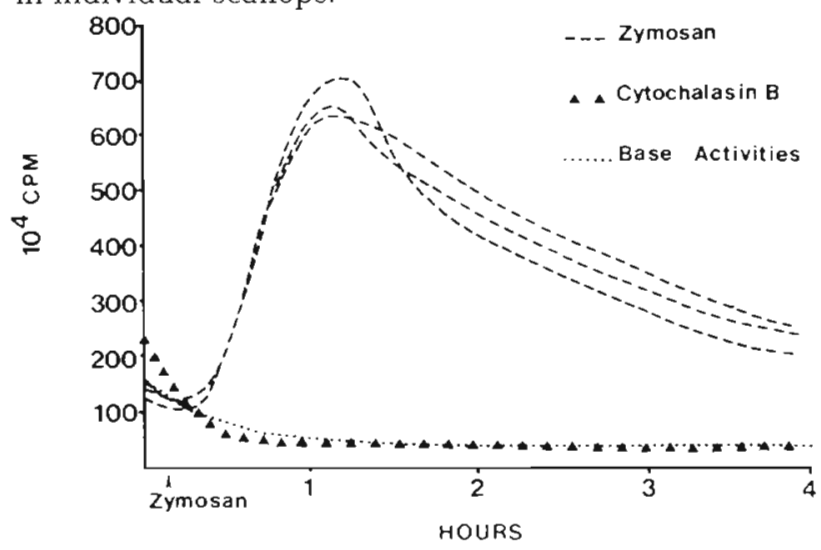

Fig. 1. Pecten maximus. Chemiluminescent responses of scallop hemocytes stimulated by zymosan (---) (particle : hemocyte ratio 80:1; 3 different scallops); pretreated by Cytochala$\sin \mathrm{B}\left(10 \mu \mathrm{g} \mathrm{m} \mathrm{l}^{-1}\right.$ final conc.) and then zymosan-stimulated ( $\mathbf{\Delta} \boldsymbol{\Delta} \mathbf{\Delta})$; non-stimulated $(\cdots \cdots)$

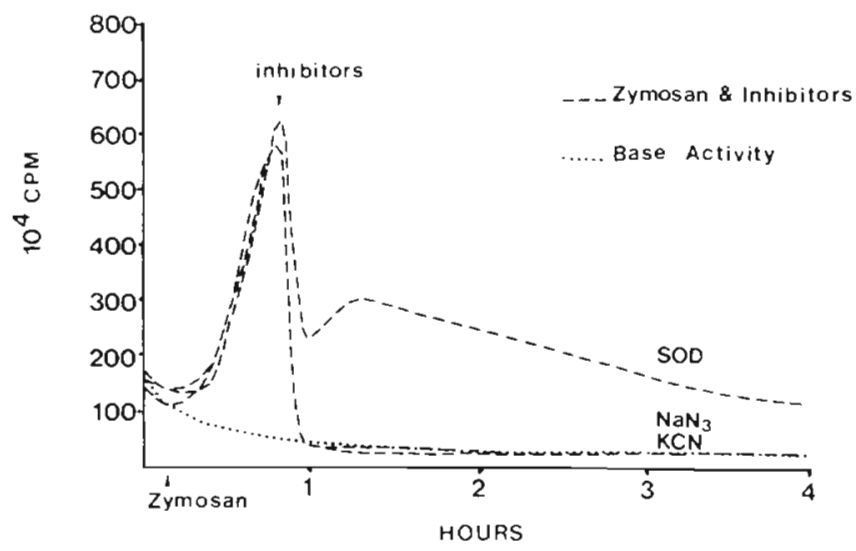

Fig. 2. Pecten maximus. Effect of inhibitors on chemiluminescent responses of scallop hemocytes stimulated by zymosan (particle: hemocyte ratio $80: 1$ ); inhibitors were $80 \mu \mathrm{g}$ SOD $\mathrm{ml}^{-1}, 10^{-3} \mathrm{M} \mathrm{NaN}_{3}$, and $10^{-3} \mathrm{M} \mathrm{KCN}$. (....) Non-stimulated
The effect of cytochalasin B on hemocyte CL activity was then examined because of the capacity of this reagent to prevent phagocytosis (Stuart et al. 1985). Preincubation of hemocytes with cytochalasin B $(10 \mu \mathrm{g}$ $\mathrm{ml}^{-1}$ ) led to a total suppression of CL response, showing the close connection between phagocytosis and hemocyte CL activity (Fig. 1).

Several respiratory burst inhibitors were tested, each hemocyte sample set being prepared from a single scallop. The addition of exogenous SOD to stimulated hemocytes caused no effect at a concentration of $10 \mu \mathrm{g}$ $\mathrm{ml}^{-1}$. However, $80 \mu \mathrm{g} \mathrm{SOD} \mathrm{ml}^{-1}$ decreased CL activity to $50 \%$ (Fig. 2). Hemocyte viability was confirmed for this last $\mathrm{SOD}$ concentration. With sodium azide $\left(\mathrm{NaN}_{3}\right)$ at $10^{-3} \mathrm{M}$, the hemocytes remained viable but their $\mathrm{CL}$ activity was immediately and completely suppressed (Fig. 2). KCN also suppressed CL response but, at the tested concentration $\left(10^{-3} \mathrm{M}\right)$, hemocyte viability was reduced by half.

\section{Hemocyte-RLO interactions}

Before studying RLO interaction with the respiratory burst of Pecten maximus hemocytes, we had examined cells by electron microscopy to determine if purified microorganisms were indeed phagocytosed. For this purpose, hemocytes were infected in vitro with purified parasites, the cells being fixed after $30 \mathrm{~min}$ and $1 \mathrm{~h}$ incubation. It appeared that RLO were phagocytosed as early as $30 \mathrm{~min}$ after introduction (Fig. 3), some hemocytes containing several microorganisms, sometimes included in the same parasitophorous vacuole. Some micrographs suggested lysis of RLO, particularly in samples fixed after $1 \mathrm{~h}$ incubation.

When live pathogens were added to vials containing hemocytes which had not been previously stimulated, no CL response was detected. Addition of live pathogens at maximal CL activity of hemocytes previously stimulated with zymosan led to a 45 to $74 \%$ decrease in luminescence (Table 1). A pretreatment of live RLO with sodium L-tartrate $\left(3.3 \times 10^{-6} \mathrm{~mol} \mathrm{ml}^{-1}\right)$ or with $\mathrm{NaN}_{3}\left(3 \times 10^{-4} \mathrm{~mol} \mathrm{ml}{ }^{-1}\right)$ led to smaller decreases in hemocyte CL activity, ranging between $50-53 \%$ and $41-56 \%$ respectively (Table 1 ).

When RLO killed by formalin were added to hemocytes, no CL activity was noticed. However, if they were added to zymosan-stimulated hemocytes at their CL activity peaks, CL activity was quickly reduced (by 28.6 to $31.5 \%$ ) to a lower level than with live RLO (Table 1). If the parasites had been killed by heat, a more marked decrease was observed (51 to $58.5 \%$; Table 1).

When RLO homogenate was added to zymosanstimulated hemocytes, CL activity was decreased by 


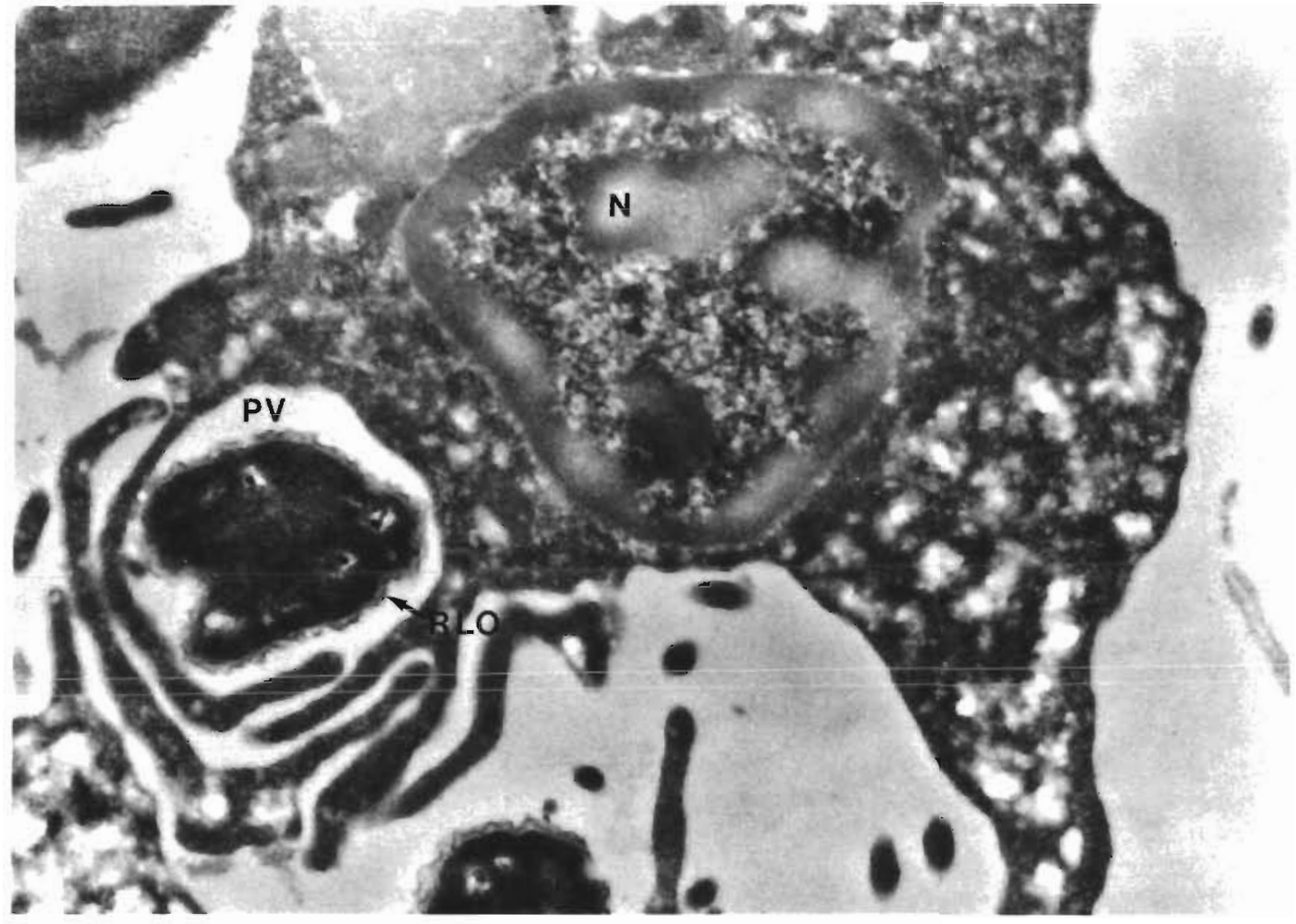

Fig. 3. Pecten maximus. Transmission electron micrograph of scallop hemocytes infected with RLO (Rickettsiales-like organism) cells and fixed $30 \mathrm{~min}$ after parasite challenge, showing progressive engulfment of RLO into a phagocytic vacuole (PV); N: hemocyte nucleus. $(\times 16000)$

Table 1. Pecten maximus. Effect of different preparations of Rickettsiales-like organisms (RLO) on CL responses of scallop hemocytes previously stimulated by zymosan (80:1), expressed as percentage of inhibition. Live or homogenated RLO were untreated (Untr.) or pretreated with $3.3 \times 10^{-6}$ mol L-tartrate $\mathrm{ml}^{-1}$ or $3.3 \times 10^{-4} \mathrm{~mol} \mathrm{NaN}_{3} \mathrm{ml}^{-1}$ RLO killed by formalin or by heat

\begin{tabular}{|cccccccc|}
\hline \multirow{2}{*}{ Expt } & \multicolumn{3}{c}{ Live } & \multicolumn{2}{c}{ Killed } & \multicolumn{2}{c|}{ Homogenated } \\
& Untr. & L-tart. & $\mathrm{NaN}_{3}$ & Formalin & Heat & Untr. & $\begin{array}{c}\text { L-tart. } \\
\text { NaN }\end{array}$ \\
\hline 1 & 72.0 & - & - & 28.6 & - & - & - \\
2 & 74.0 & - & - & 31.5 & - & - & - \\
3 & 48.0 & 50.0 & 41.0 & - & 58.5 & - & - \\
4 & 45.0 & 53.0 & 56.0 & 29.0 & 51.0 & 63.0 & 55.0 \\
\hline
\end{tabular}

$63 \%$; when the homogenate had been preincubated in sodium L-tartrate $\left(3.3 \times 10^{-6} \mathrm{~mol} \mathrm{ml}^{-1}\right)$ or in $\mathrm{NaN}_{3}$ $\left(3 \times 10^{-4} \mathrm{~mol} \mathrm{ml}^{-1}\right)$, activity decreased by 55 and $56 \%$ respectively (Table 1 ).

\section{DISCUSSION}

This in vitro study of interactions between RLO and host was initially based on an analysis of oxidative metabolism in Pecten maximus hemocytes. The experimental parameters established for oyster hemocytes, using hemolymph withdrawals with antiaggregant solution and low $\left(10^{-4} \mathrm{M}\right)$ luminol concentration (Bachère et al. 1991), were perfectly suited for scallop hemo- cytes. The number of hemocytes contained in each counting vial was fixed at $2 \times 10^{5}$ because good CL signals were obtained and several similar samples from a single hemolymph withdrawal could be prepared. Consequently, by comparing CL activities of hemolymph samples from a single scallop, inter-individual variability was excluded. Thus, if the observed variation in individual CL activities was not caused by methodological factors, it may be suggested that qualitative differences in hemograms were the cause. This hypothesis could be tested by analysing CL activity of each hemocyte type, separated beforehand by isopycnic centrifugation and centrifugal elutriation (Bachère et al. 1988), or by immunopurification using specific monoclonal antibodies. 
The CL activity of Pecten maximus hemocytes was differentially inhibited by SOD, $\mathrm{NaN}_{3}$ and KCN. SOD is known to catalyse the decomposition of superoxide anion $\left(\mathrm{O}_{2}^{-}\right.$) into $\mathrm{O}_{2}$ and $\mathrm{H}_{2} \mathrm{O}_{2}$ (McCord \& Fridovich 1969). The CL inhibition observed when SOD was used at $80 \mu \mathrm{g} \mathrm{ml}^{-1}(50 \%$ ) (as opposed to no effect at $10 \mu \mathrm{g}$ $\mathrm{ml}^{-1}$ ) is consistent with data concerning luminolenhanced CL for human neutrophils (De Chatelet et al. 1982), murine polymorphonuclear granulocytes and macrophages (Müller-Peddinghaus 1984, Vincendeau et al. 1988) and gastropod hemocytes (Dikkeboom et al. 1987, 1988). $\mathrm{NaN}_{3}$ inhibits myeloperoxidase (MPO) (Nakagawara et al. 1981) and catalase, and has a quencher effect on singlet oxygen $\left({ }^{1} \mathrm{O}_{2}\right)$ (Rosen \& Klebanoff 1977). At similar tested concentrations, the results obtained for $P$. maximus hemocytes were in agreement with those previously cited. Also, the complete inhibition of $\mathrm{CL}$ by $\mathrm{KCN}$, an inhibitor of $\mathrm{SOD}$, MPO and catalase (McCord \& Fridovich 1969, Nakagawara et al. 1981), corresponds to data acquired by De Chatelet et al. (1982) and Müller-Peddinghaus (1984) in human and murine phagocytes. Therefore, these results indicate that $P$. maximus hemocytes produce, during phagocytosis, oxygen radicals as do vertebrate phagocytic cells.

Because the reactive oxygen species are well known in vertebrates as strong microbicidal parasiticidal effectors (Klebanoff 1968, 1982, Babior 1978, Nakagawara et al. 1981), their involvement in rickettsiosis specific to Pecten maximus was worth analysing. Indeed, although RLO infect the gill endothelial cells, they have an extracellular phase in the hemolymph which may be related to the infection process of new cells. Moreover, infections are quickly established and heavy in young scallops reared in infected areas, which suggests that their defense mechanism is relatively ineffective. Prior to CL experiments, the phagocytosis of rickettsias by $P$. maximus hemocytes was established by electron microscopy. Some micrographs suggested an intravacuolar disintegration of the RLO.

Despite this patent in vitro phagocytosis process, chemiluminescence experiments showed no production of free oxygen radicals by RLO-stimulated hemocytes. Thus, either RLO do not trigger cell respiratory burst or they possess a highly efficient scavenger system. This last hypothesis was supported by experiments with zymosan-stimulated hemocytes, subsequently incubated with live, killed or homogenated parasites. A substantial interference of the host hemocyte oxidative metabolism was observed, whatever the type of RLO suspension. The relatively slight inhibition shown by heat- or formalin-killed parasites compared to live or homogenized parasites suggested denaturation of the CL inhibitors.

Many intracellular pathogens associated with mac- rophages are adapted enzymatically to survive in this deleterious environment. Enzymes such as SOD, catalase (Weiss et al. 1987) and glutathione peroxidase (Mkoji et al. 1988) have been shown to play a prominent role in protecting parasites against host respiratory burst and may be responsible for this adaptive strategy. It is also suggested that acid phosphatase, recently demonstrated in Pecten maximus RLO (Le Gall et al. unpubl. data) and particularly well-studied in Leishmania parasites (Gottlieb \& Dwyer 1981, Glew et al. 1982), reduces the ability of the phagocytic cell to produce superoxide anions (Remaley et al. 1984). In CL experiments, inhibition of $P$. maximus hemocyte respiratory burst was decreased if RLO were incubated with L-tartrate, an inhibitor of some acid phosphatases. The influence of $\mathrm{NaN}_{3}$ on hemocyte respiratory burst inhibition may be the result of a pathogen peroxidase However, its function will have to be defined by chemical characterization.

In conclusion, the interactions between scallops and RLO can now be analysed from an immunological point of view using experiments at the cellular level. It is possible to estimate the defense mechanism of individual scallops without killing them by using $\mathrm{CL}$ techniques performed on hemolymph samples. Such a methodology is particularly suitable for investigating the hemocyte responses of scallops of different ages. Indeed, transmission of rickettsial-like infection is horizontal, and juveniles become infected when placed in a contaminated area (Le Gall et al. 1991). It is possible that juvenile sensitivity is correlated with an undifferentiated defense mechanism system, as suggested by Leibovitz (1989) for chlamydiosis in Argopecten irradians. This disease is fatal for juveniles, whereas only mild for adults.

The mechanism of inhibition of host hemocyte respiratory burst by RLO needs to be defined in more detail. The actual survival of parasites should be analysed using long term in vitro culture of hemocytes infected with purified procaryotes. However, the preliminary results described in this paper may explain the short-term survival in hemolymph, which is required by rickettsias for dispersal to host cells after disruption of parasitophorous vacuoles.

Acknowledgements. We are grateful to Dr W. P. W. Van Der Knaap for constructive criticism of this manuscript and D Chagot for her technical assistance in electron microscopy.

\section{LITERATURE CITED}

Allen, R. C., Loose, L. D. (1976). Phagocytic activation of a luminol-dependent chemiluminescence in rabbit alveolar and peritoneal macrophages. Biochem. biophys. Res. Commun. 69: 245-252 
Allen, R. C., Stjernholm, R. L., Steele, R. H. (1972). Evidence for the generation of an electronic excitation state(s) in human polymorphonuclear leucocytes and its participation in bactericidal activity. Biochem. biophys Res. Commun. 47: 679-684

Anderson. R. S. (1977). Biochemistry and physiology of invertebrate macrophages in vitro. In: Bulla, L. A., Cheng, I C. (eds.) Comparative pathobiology, Vol. 3. Plenum Press, New York and London, p. 1-20

Babior, B. M. (1978). Oxygen-dependent microbial killing by phagocytes. New Engl. J. Med. 298: 659-668

Bachère, E., Chagot, D., Grizel, H. (1988). Separation of Crassostrea gigas hemocytes by density gradient centrifugation and counterflow centrifugal elutriation. Devl comp. Immun. 12: 549-559

Bachère, E., Hervio, D., Mialhe, E. (1991), Luminol-dependent chemiluminescence by hemocytes of two marine bivalve species, Ostrea edulis and Crassostrea gigas. Dis. aquat. Org. (in press)

Bang, F. B. (1975). Phagocytosis in invertebrates. In: Maramorosch, K., Shope, R. E. (eds.) Invertebrate immunity. Academic Press, New York, p. 137-151

Buchanan, J. S. (1978). Cytological studies on d new species of rickettsia found in association with a phage in the digestive gland of the marine bivalve mollusc. Tellina tenuis (da Costa). J. Fish Dis. 1: 27-43

Comps, M., Raimbault, R. (1978). Infection rickettsienne de la glande digestive de Donax trunculus L. Sci. Pêche 281: $11-12$

De Chatelet, L. R., Long, G. O., Shirley, P. S., Bass, D. A., Thomas, M. J., Henderson, F. W., Cohen, M. S. (1982). Mechanisms of the luminol-dependent chemiluminescence of human neutrophils. J. Immunol. 129: 1589-1593

Dikkeboom, R., Tijnagel, J. M. G. H., Mulder, E. C., Van Der Knaap, W P. W. (1987). Hemocytes of the pond snail Lymnaea stagnalis generate reactive forms of oxygen. J. Invertebr. Pathol. 49: 321-331

Dikkeboom, R., Van Der Knaap, W. P. W., Van Den Bovenkamp, W., Tijnagel, J. M. G. H., Bayne, C. J. (1988). The production of toxic oxygen metabolites by hemocytes of different snail species. Devl comp. Immun. 12: 509-520

Glew, R. H., Czuczman, M. S., Diven, W F., Berens, R. L., Pope, M. T., Katsoulis, D. E. (1982). Partial purification and characterization of particulate acid phosphatase of Leishmania donovani promastigotes. Comp. Biochem. Physiol. 72B: $581-590$

Gottlieb, M., Dwyer, D. M. (1981). Leishmania donovani: surface membrane acid phosphatase activity of promastigotes. Exp. Parasitol. 52: 117-128

Gulka, G., Chang, P. W., Marti, K. A. (1983). Procaryotic infection associated with a mass mortality of the sea scallop Placopecten magellanicus. J. Fish Dis. 6: 355-364

Klebanoff, S. J. (1968). Myeloperoxidase-halide-hydrogen peroxide antibacterial system. J. Bacteriol. 95: 2131-2138

Klebanoff, S. J. (1982). Oxygen-dependent cytotoxic mechanisms of phagocytes. In: Gallin, J. I., Fauci, A. S. (eds.) Advances in host defense mechanisms, Vol.1 Raven Press, New York, p. 111-162

Larson, K. G., Roberson, B. S., Hetrick, F. M. (1989). Effect of environmental pollutants on the chemiluminescence of hemocytes from the American oyster Crassostrea virginica. Dis. aquat. Org. 6: 131-136

Le Gail. G., Bachǹre, E., Mialhe, E., Grizel, H. (1989). Zymo-

Responsible Subject Editor: A. K. Sparks, Seattle, Washington, USA san and specific-rickettsia activation of oxygen free radicals production in Pecten maximus hemocytes. Devi comp. Immun. 13: 448

Le Gall, G., Chagot, D., Mialhe, E. Grizel, H. (1988). Branchiā Rickettsiales-like infection assoclated with mass mortality of sea scallop Pecten maximus. Dis. aquat. Org. 4: 229-232

Le Gall, G., Mialhe, E., Chagot, D., Grizel, H. (1991). Epizootiological study of rickettsiosis of the Saint-Jacques scallop Pecten maximus. Dis. aquat. Org. 10: 139-145

Leibovitz, L. (1989). Chlamydiosis: a newly reported serious disease of larval and postmetamorphic bay scallops, Argopecten irradians (Lamarck). J. Fish Dis. 12: 125-136

McCord, J. M., Fridovich, I. (1969). Superoxide dismutase: an enzymic function for erythrocuprein (Hemocuprein). J. biol. Chem. 244: 6049-6055

Mkoji, G. M., Smith, J. M., Pritchard, R. K. (1988). Antioxidant systems in Schistosoma mansoni: evidence for their role in protection of the adult worms against oxidant killing. Int. J. Parasit. 18: 667-673

Müller-Peddinghaus, R. (1984). In vitro determination of phagocyte activity by luminol- and lucigenin-amplified chemiluminescence. Int. J. Immunopharmac. 6: 455-466

Nakagawara, A., Nathan, C F, Cohn, Z. A. (1981). Hydrogen peroxide metabolism in human monocytes during differentiation in vitro. J, clin. Invest. 68: 1243-1252

Nakamura, M., Mori, K., Inooka, S., Nomura, T. (1985). In vitro production of hydrogen peroxide by the amoebocytes of the scallop, Patinopecten yessoensis (Jay). Devl comp. Immun. 9: 407-417

Parks, D. R., Bryan, V. M., Oi, V T., Herzenberg, L. A. (1979). Antigen specific identification and cloning of hybridomas with a fluorescence activated cell sorter (FACS). Proc. natl Acad. Sci. U.S.A. 76: 1962

Prendergast, E., Proctor, R. A. (1981). Simple procedure for measuring neutrophil chemiluminescence. J. clin. Microbiol. 13: 390-395

Remaley, A. T., Kuhns, D. B., Basford, R. E., Glew, R. H., Kaplan, S. S. (1984). Leishmanial phosphatase blocks neutrophil $\mathrm{O}^{2-}$ production. J. biol. Chem. 259: 11 173-11 175

Roos, D. (1980). The metabolic response to phagocytosis. In Weissman, G. (ed.) The cell biology of inflammation. Elsevier, North-Holland Biomedical Press, Amsterdam, p. $337-385$

Rosen, H. Klebanoff, S. J. (1977). Formation of singlet oxygen by the myeloperoxidase-mediated antimicrobial system. J. biol. Chem. 252: 4803-4810

Shozawa, A. (1986). A reducing factor produced by haemocytes of Biomphalaria glabrata and its role in the host defence. Devl comp. Immun. 10:636

Sminia, T., Van Der Knaap, W. P. W (1987). Cells and molecules in molluscan immunology. Devl comp. Immun. 11: $17-28$

Stuart, J., McRobbie, M. N., Newell, P. C. (1985). Effects of cytochalasin B on cell movements and chemoattractantelicited actin changes of Dictyostelium. Expl Cell Res. 160: $275-286$

Thomas, E. L., Lehrer, R. I., Rest, R. F. (1988). Human neutrophil antimicrobial activity. Rev. infect. Dis. 10:450-456

Vincendeau, P., Daulouede, S., Veyret, B. 11988\}. Role of hypochlorous acid in Trypanosoma musculi killing by phagocytes. Parasitol. 98: 253-257

Weiss, E., Dobson, M. E., Dasch, G. A. (1987). Biochemistry of rickettsiae: recent advances. Acta Virol. 31 271-286

Manuscript first received: December 4, 1990

Revised version accepted: August 13, 1991 